\title{
MCM-41 Ordered Mesoporous Molecular Sieves Synthesis and Characterization
}

\author{
Rogério A.A. Melo ${ }^{\mathrm{a}}$, Marcus V. Giotto ${ }^{\mathrm{a}}$, João Rocha ${ }^{\mathrm{b}}$, \\ Ernesto A. Urquieta-González ${ }^{\mathrm{a}}$ \\ ${ }^{a}$ Departamento de Engenharia Química, Universidade Federal de São Carlos, \\ C.P. 676, 13565-905 São Carlos - SP, Brazil \\ ${ }^{\mathrm{b}}$ Departamento de Química, Universidade de Aveiro, 3810 Aveiro, Portugal
}

Received: August 15, 1998; Revised: March 30, 1999

\begin{abstract}
The aim of this work was to study the hydrothermal synthesis of Si and SiAlMCM-41 performed under both autogenic pressure and refluxing conditions. XRD data showed that the MCM-41 phase may be formed by both processes and that the synthesized material in the presence of $\mathrm{Al}$ and/or under reflux presents the hexagonally arrangement of less ordered mesopores. However, as verified by XRD and physisorption data, the order was improved with higher synthesis times. ${ }^{29} \mathrm{Si}$ and ${ }^{1} \mathrm{H}$ ${ }^{29} \mathrm{Si}$ C/P MAS NMR spectra showed that a great part of the $\mathrm{Si}$ atoms exists as silanol groups which originate resonance peaks at $-110,-100$ and $-91 \mathrm{ppm}$. The presence of $\mathrm{Al}$ atoms may generate $\mathrm{Si}(3 \mathrm{Si}$, $\mathrm{Al})$ and $\mathrm{Si}(2 \mathrm{Si}, 2 \mathrm{Al})$ environments which might be contributing to resonance peaks at -100 and -91 ppm. The ${ }^{27}$ Al MAS NMR spectrum of the as synthesized AlSiMCM-41 showed a resonance peak of tetrahedral framework aluminum close to $53 \mathrm{ppm}$ and two others, one close to $14 \mathrm{ppm}$ attributed to $\mathrm{Al}\left(\mathrm{H}_{2} \mathrm{O}\right)_{6}{ }^{+3}$ species and the other a weak signal close to $32 \mathrm{ppm}$ attributed to pentacoordinated Al. ${ }^{27} \mathrm{Al}$ MAS NMR spectra of the calcined sample showed a peak at $0 \mathrm{ppm}$ corresponding to an hexacoordinated extra-framework aluminum formed during calcination.
\end{abstract}

Keywords: $M C M-41$, synthesis, characterization

\section{Introduction}

Molecular sieves with a zeolite structure and pore diameter $<15 \AA$ exhibit a shape selectivity that enables them to be used as adsorbents or catalysts in a variety of processes. However, reactions involving bulky molecules require structures with channel diameters at mesopore scale. In the early nineties ${ }^{1,2}$, scientists from Mobil Oil Corporation synthesized ordered mesoporous materials of the M41S type, family to which MCM-41 belongs. This material possesses a porous system consisting of hexagonally arranged channels with diameters varying from 15 to $100 \AA$. MCM- 41 has attracted the attention of scientists due to its elevated specific surface area, high thermal and hydrothermal stability, possibility of controlling its pore size and its hydrophobicity and acidity. These characteristics have made MCM-41 a promising material as catalyst and/or support ${ }^{3}$ and to be used in industrial processes of adsorption ${ }^{4}$, ion exchange $e^{5}$ and environmental control ${ }^{6}$.
The scope of the current work was to investigate the hydrothermal synthesis of SiMCM-41 and AlSiMCM-41 performed under both autogenic pressure and refluxing conditions. The solids obtained were characterized by XRD, SEM, nitrogen physisorption TGA/DTG, ${ }^{29} \mathrm{Si}$ MAS NMR; ${ }^{1} \mathrm{H}-{ }^{29} \mathrm{Si} \mathrm{CP} / \mathrm{MAS}$ NMR and ${ }^{27} \mathrm{Al}$ MAS NMR.

\section{Materials and Methods}

\subsection{Synthesis of MCM-41}

The molar compositions ${ }^{1,2,7}$ and synthesis times used are listed in Table 1. The used precursors consisted basically of amorphous silica (Aerosil-200/Degussa); sodium trisilicate (Aldrich); tetramethylammonium hydroxide (Aldrich); sodium aluminate (Riedel De Haën); cetyltrimethylammonium bromide (Merck) and distilled water. Part of the reaction mixture was placed in teflon cups inside of steel autoclaves being subsequently submitted to hydrothermal treatment under autogenic pressure in a oven at $100{ }^{\circ} \mathrm{C}$. The remaining part was treated at the same tem- 
Table 1. Molar compositions and synthesis time.

\begin{tabular}{lccc}
\hline Samples & Composition & $\begin{array}{c}\text { Reflux } \\
\mathrm{Y}(\mathrm{h})\end{array}$ & $\begin{array}{c}\text { Aut Pres } \\
\mathrm{Y}(\mathrm{h})\end{array}$ \\
\hline SiMCM-41 & $\mathrm{SiO}_{2}: 0.07 \mathrm{Na}_{2} \mathrm{O}: 0.27 \mathrm{CTMA}: 0.14 \mathrm{TMAOH}: 100 \mathrm{H}_{2} \mathrm{O}$ & $24 ; 108$ & $48 ; 288$ \\
AlSiMCM-41 & $\mathrm{SiO}_{2}: 0.025 \mathrm{Al}_{2} \mathrm{O}_{3}: 0.07 \mathrm{Na}_{2} \mathrm{O}: 0.27 \mathrm{CTMA}: 0.14 \mathrm{TMAOH}: 100 \mathrm{H}_{2} \mathrm{O}$ & $24 ; 108$ & $48 ; 288$ \\
\hline
\end{tabular}

perature under refluxing conditions. After the synthesis the solids were separated from the reaction mixture through centrifugation, washed and dried at $110^{\circ} \mathrm{C}$. Removal of the organic material occurred by calcination at $550{ }^{\circ} \mathrm{C}$ under nitrogen flow $\left(100 \mathrm{~cm}^{3} / \mathrm{min} \mathrm{g}\right)$ for $1 \mathrm{~h}$ and subsequently under synthetic air flow $\left(100 \mathrm{~cm}^{3} / \mathrm{min} \mathrm{g}\right)$ for $6 \mathrm{~h}$. The samples were designated as SiMCM-41(X/Y) and AlSiMCM-41(X/Y), where $\mathrm{X}=\mathrm{P}$ presents the samples obtained under autogenic pressure and $\mathrm{X}=\mathrm{R}$ under refluxing conditions; Y corresponds to the synthesis time in hours.

\subsection{Characterization}

X-ray powder diffraction patterns were recorded on a Siemens D500 diffractometer using a monochromated $\mathrm{CuK}_{\alpha}$ radiation in the angular range from 1 to $10^{\circ}(2 \theta)$; the $2 \theta$ scanning speed was $0.6 \% \mathrm{~min}$. The scanning electron micro-analysis was performed on a Zeiss DSM 960 Scanning Electron Microscope operated at $30 \mathrm{kV}$. Thermogravimetric analysis was carried out on a Thermal Analyst 2100 TA Instruments equipment in the temperature range from 30 to $900^{\circ} \mathrm{C}$ (heating rate $3{ }^{\circ} \mathrm{C} / \mathrm{min}$ ) in $\mathrm{O}_{2}$ flow (30 $\mathrm{cm}^{3} / \mathrm{min}$ ). Nitrogen physisorption measurement at $-196{ }^{\circ} \mathrm{C}$ was conducted on a NOVA 1200 TGA Quantachrome Corporation analyzer. Solid state ${ }^{29} \mathrm{Si}$ MAS NMR spectra were recorded on a Varian $400 \mathrm{MHz}$ spectrometer at 79.5 $\mathrm{MHz}$ with $50^{\circ}$ pulses $(4.3 \mu \mathrm{s})$ and $5 \mathrm{kHz}$ spinning rates. The recycle delay was $100 \mathrm{~s}$. The ${ }^{1} \mathrm{H}-{ }^{29} \mathrm{Si}$ C/P MAS NMR spectrum was recorded with $4.5 \mu \mathrm{s}{ }^{1} \mathrm{H}\left(90^{\circ}\right)$ pulses with a contact time of $5 \mathrm{~ms}$ and $5 \mathrm{~s}$ of recycle delay. The ${ }^{27} \mathrm{Al} \mathrm{MAS}$ NMR spectra were recorded on a Bruker MSL 400P spectrometer operating at $104.2 \mathrm{MHz}$ with $0.6 \mathrm{~s}(\pi / 18)$ pulses and a recycle delay of $0.8 \mathrm{~s}$.

\section{Results and Discussion}

\subsection{X-ray powder diffraction}

$\mathrm{XRD}$ analysis of the as synthesized samples indicated that the mesoporous MCM-41 molecular sieve may be obtained by both processes and allowed identification of the peaks relative to the (100), (110), (200) and (210) planes corresponding to an hexagonal structure with symmetry P6 for the reflection planes (hk0), indicating that there are no planes for $1 \neq 0^{1,2}$. The values of the parameter $a_{o}$ of the hexagonal pore arrangement for different samples are sum- marized in Table 2. These values are seen to be very representative compared to those presented by other authors who used the same surfactant ${ }^{8}$. The parameter $a_{o}$ is also seen to show a tendency to increase with synthesis time for both processes, which has been attributed to the increase in the wall thickness of the mesopores ${ }^{9}$.

Figure 1 shows X-ray diffraction patterns for samples SiMCM-41 and AlSiMCM-41 synthesized in $48 \mathrm{~h}$. The diffraction peak related to the (100) plane is seen to be more
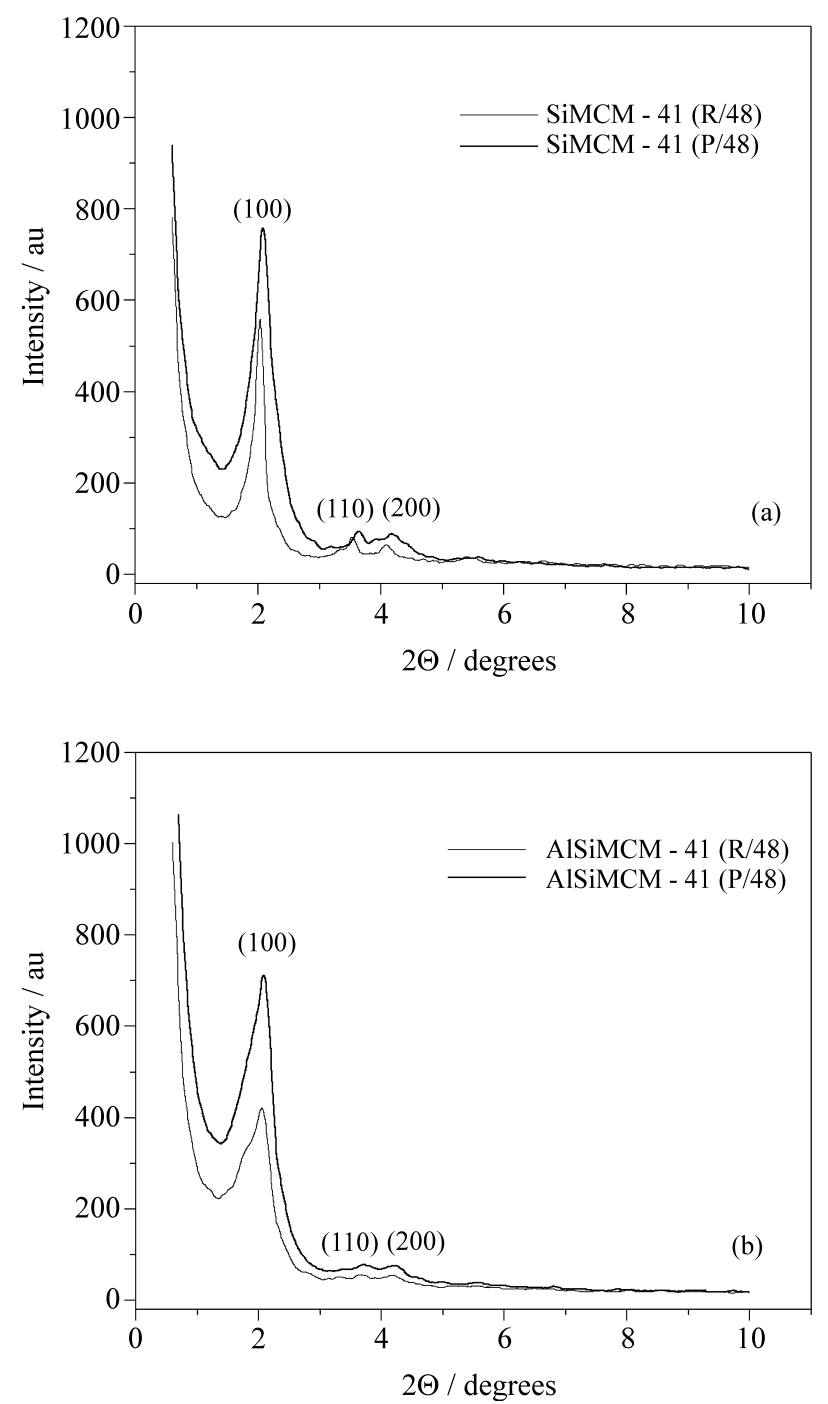

Figure 1. XRD of the as synthesized: a) SiMCM-41, and b) AlSiMCM-41 samples. 
Table 2. Parameter an for SiMCM-41 and AlSiMCM-41 samples.

\begin{tabular}{lc}
\hline Samples & $\mathrm{a}_{0}(\AA)$ \\
\hline SiMCM-41(R/24) & 45.85 \\
SiMCM-41(R/108) & 46.07 \\
SiMCM-41(P/48) & 45.54 \\
SiMCM-41(P/288) & 47.59 \\
AlSiMCM-41(R/24) & 45.75 \\
AlSiMCM-41(R/108) & 45.32 \\
AlSiMCM-41(P/48) & 45.95 \\
AlSiMCM-41(P/288) & 48.16 \\
\hline
\end{tabular}

intense for samples obtained under autogenic pressure when compared to those obtained under reflux, which can be interpreted as an indication of higher ordering of the mesopore channels ${ }^{10}$. The materials synthesized in the presence of aluminum exhibit broader and slightly less intense diffraction peaks, indicating that within $48 \mathrm{~h}$ synthesis, the hexagonal arrangement of the mesopores in these materials is less ordered compared to SiMCM-41

\subsection{Nitrogen physisorption}

The adsorption/desorption isotherms of $\mathrm{N}_{2}$ (Fig. 2) and the values of specific surface area $\left(\mathrm{S}_{\mathrm{BET}}\right)$, mean diameter of the mesopores $\left(\mathrm{d}_{\mathrm{mp}}\right)$, total volume of pores $\left(\mathrm{V}_{\mathrm{t}}\right)$ and wall thickness $(\varepsilon)$ obtained for calcined SiMCM-41 (Table 3) are in agreement with those published by other authors ${ }^{11}$. Curves in Fig. 2 and data from Table 3 show an increase in the adsorption capacity of $\mathrm{N}_{2}$ with time for the SiMCM-41 samples synthesized under reflux, indicating an improvement in the order of the mesopore phase, already observed by the increase in the XRD peak intensity (Fig. 3). However, as it has been observed from the data in Fig. 1, the MCM-41 phase is formed more readily under autogenic pressure, showing a small dependence with synthesis time, as it can be seen in Fig. 4 and from the data in Table 3.

\subsection{TG/DTG analysis}

Thermogravimetric analysis of the as synthesized AlSiMCM-41(P/288) sample presented a DTG curve typical of MCM-41 (Fig. 5). The as synthesized material presents approximately $50 \mathrm{wt} \%$ of the MCM-41 phase. The remaining part corresponds to organic material whose mass loss is related to three exothermal stages: (a) between 100$285^{\circ} \mathrm{C}$ : decomposition of the surfactant ${ }^{2}$; (b) between $285-$ $400{ }^{\circ} \mathrm{C}$ : breaking of the hydrocarbon chain, and (c) between 500-700 ${ }^{\circ} \mathrm{C}$ : combustion of the surfactant and water loss associated with condensation of silanol groups ${ }^{12}$.
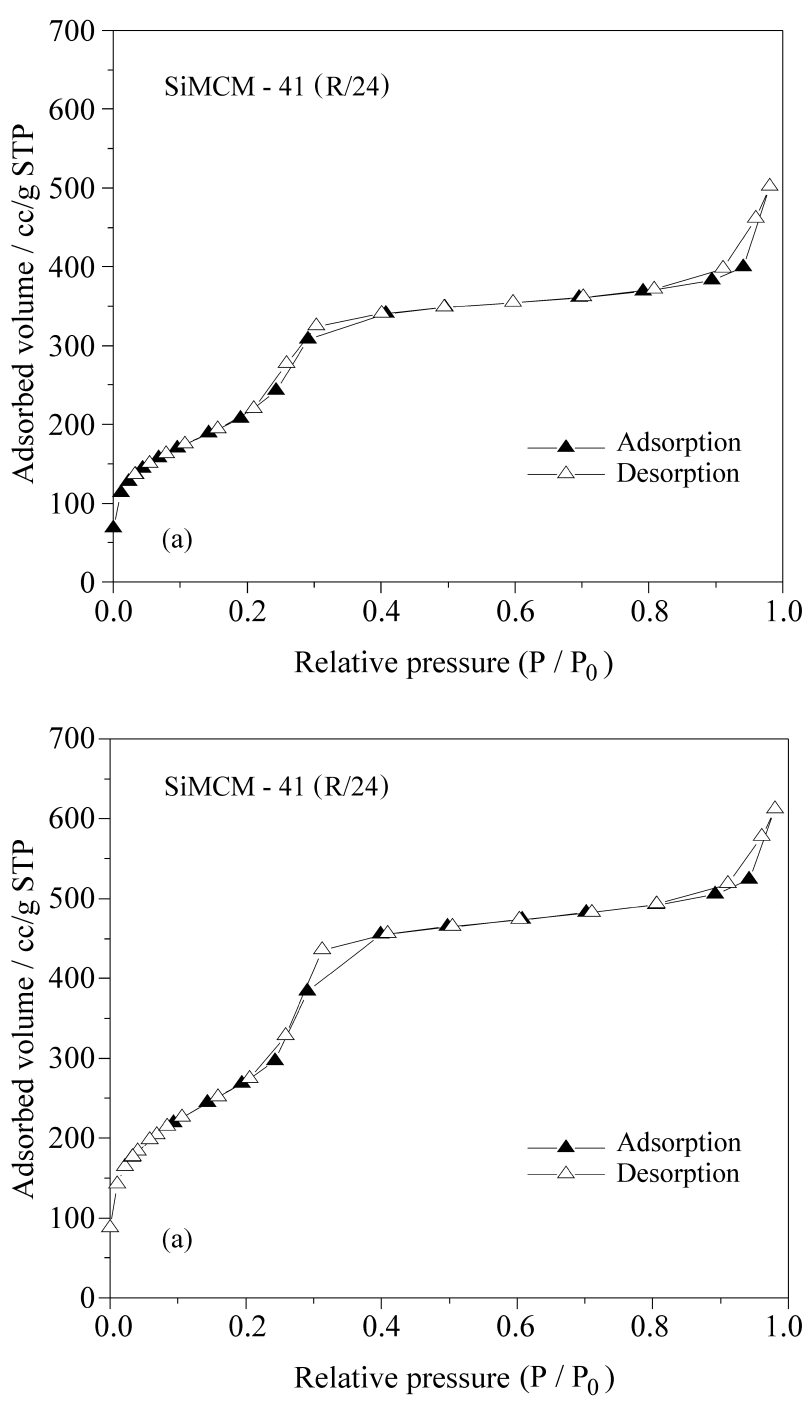

Figure 2. Adsorption/desorption isotherms of $\mathrm{N}_{2}$ for calcined SiMCM-41 samples.

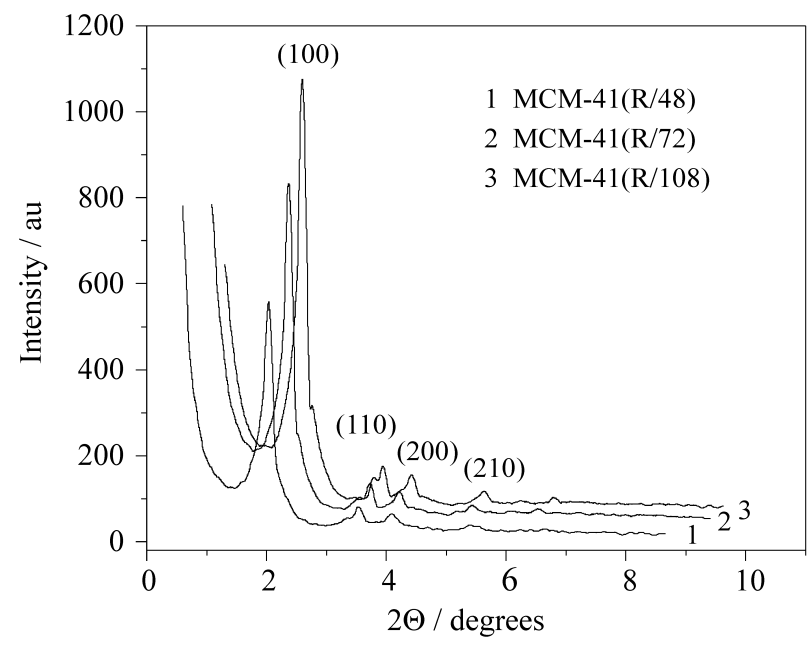

Figure 3. XRD of the as synthesized SiMCM-41(R/Y) samples. 
Table 3. Textural characteristics of the calcined SiMCM-41 samples.

\begin{tabular}{lcccc}
\hline Sample & $\begin{array}{c}\text { Average diameter of the } \\
\text { mesopores } \\
\mathrm{d}_{\mathrm{mp}}(\AA)\end{array}$ & $\begin{array}{c}\text { Wall thickness } \\
\varepsilon^{*}(\AA)\end{array}$ & $\begin{array}{c}\text { Area SBET } \\
\left(\mathrm{m}^{2} / \mathrm{g}\right)\end{array}$ & $\begin{array}{c}\text { Total pore volume } \\
\left(\mathrm{V}_{\mathrm{t}}\right)\left(\mathrm{cm}^{3} / \mathrm{g}\right)\end{array}$ \\
\hline SiMCM-41(R/24) & 35.34 & 10.51 & 876 & 0.77 \\
SiMCM-41(R/108) & 34.74 & 11.33 & 1087 & 0.94 \\
SiMCM-41(P/48) & 36.48 & 9.08 & 941 & 0.86 \\
SiMCM-41(P/288) & 34.90 & 12.69 & 978 & 0.85 \\
\hline
\end{tabular}

$\varepsilon=\mathrm{a} 0_{0}-\mathrm{d}_{\mathrm{mp}}$.

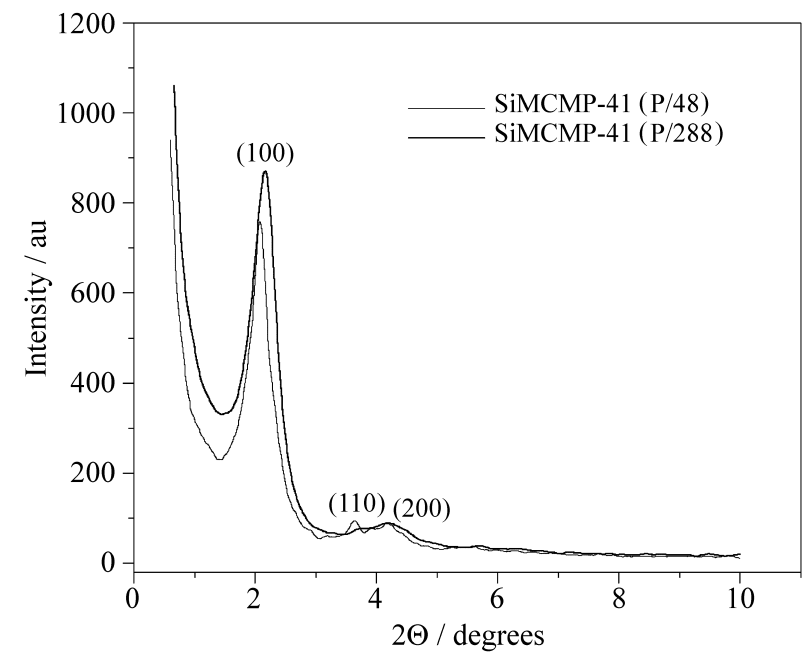

Figure 4. XRD of the as synthesized SiMCM-41(P/Y) samples.

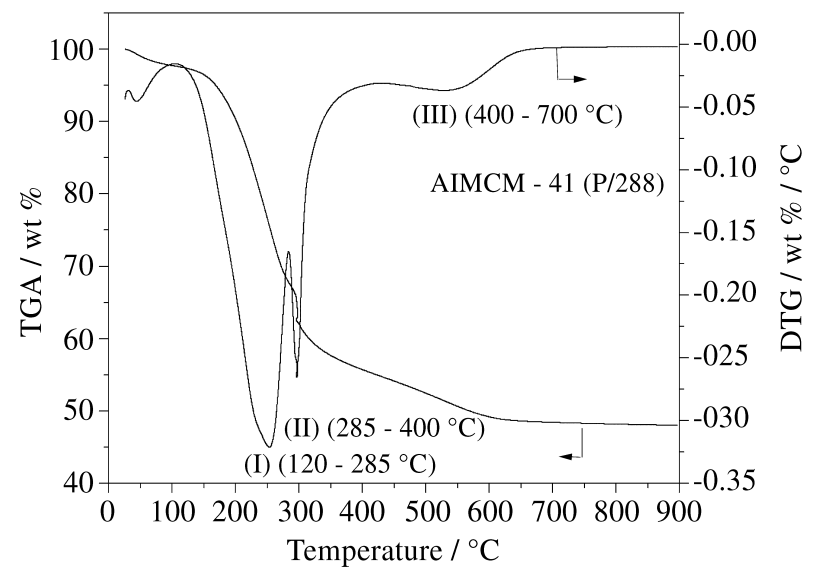

Figure 5. TGA-DTG analysis of the as synthesized AlSiMCM-41 (P/288) sample.

\subsection{NMR spectra}

The ${ }^{29} \mathrm{Si}$ MAS NMR spectra of the as synthesized and calcined AlSiMCM-41(R/108) samples, shown in Fig. 6 bears much resemblance to that of amorphous silica, indi-

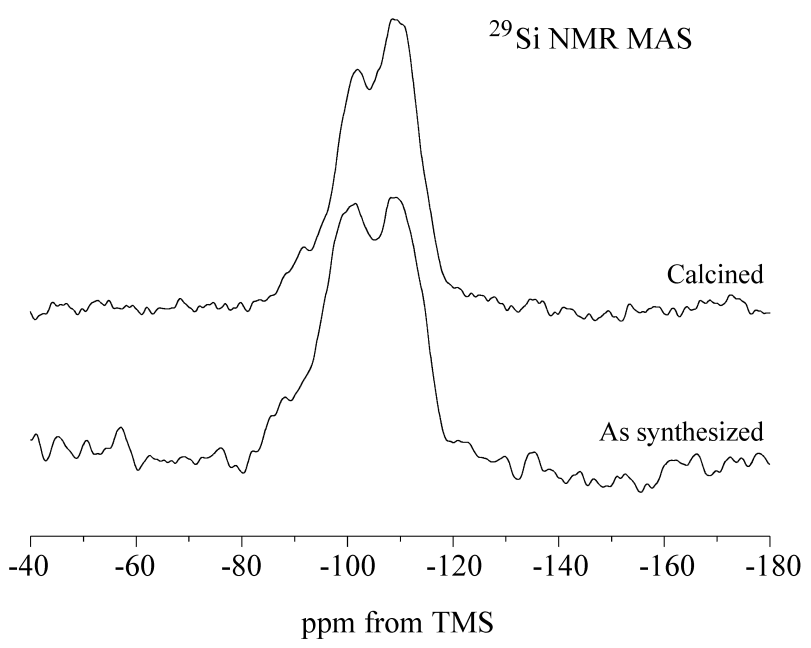

Figure 6. ${ }^{29} \mathrm{Si}$ MAS NMR spectra of the AISiMCM-41 (R/108) samples.

cating that the local arrangement of the Si-O-Si bonds at the pore walls is irregular and that the angle between these bonds vary over a wide range. The ${ }^{1} \mathrm{H}-{ }^{29} \mathrm{Si} \mathrm{CP} / \mathrm{MAS}$ NMR spectrum (Fig. 7) of the calcined sample, shows that, similar to amorphous silica, part of the $\mathrm{Si}$ atoms exist as silanol groups which originate resonance peaks at $-110,-100$ and $-91 \mathrm{ppm}$. These shifts have been attributed to the $\mathrm{Si}(4 \mathrm{SiO})$, $\mathrm{Si}(\mathrm{OSi})_{3} \mathrm{OH}$ and $\mathrm{Si}(\mathrm{OSi})_{2}(\mathrm{OH})_{2}$ environments. Chemical analysis of this sample supplied a ratio $\mathrm{Si} / \mathrm{Al}=9$. The presence of $\mathrm{Al}$ atoms in the MCM-41 network may generate $\mathrm{Si}(3 \mathrm{Si}, \mathrm{Al})$ and $\mathrm{Si}(2 \mathrm{Si}, 2 \mathrm{Al})$ environments, which might be contributing to the resonance peak intensities at -100 and $-91 \mathrm{ppm}^{13}$.

The ${ }^{27}$ Al MAS NMR spectra of the as synthesized and calcined AlSiMCM-41(R/108) samples (Fig. 8), present a resonance peak close to $53 \mathrm{ppm}$ which is attributed to structural tetrahedral coordinated aluminum. The as synthesized sample shows one peak close to $14 \mathrm{ppm}$ and a weak signal at $32 \mathrm{ppm}$, which have been attributed to hexacoordinated aluminum, possibly forming $\mathrm{Al}\left(\mathrm{H}_{2} \mathrm{O}\right)_{6}{ }^{3+}$ species within the pores and pentacoordinated species, respectively. These resonances were not detected in the calcinated sample ${ }^{13}$. For the calcined sample the peak 


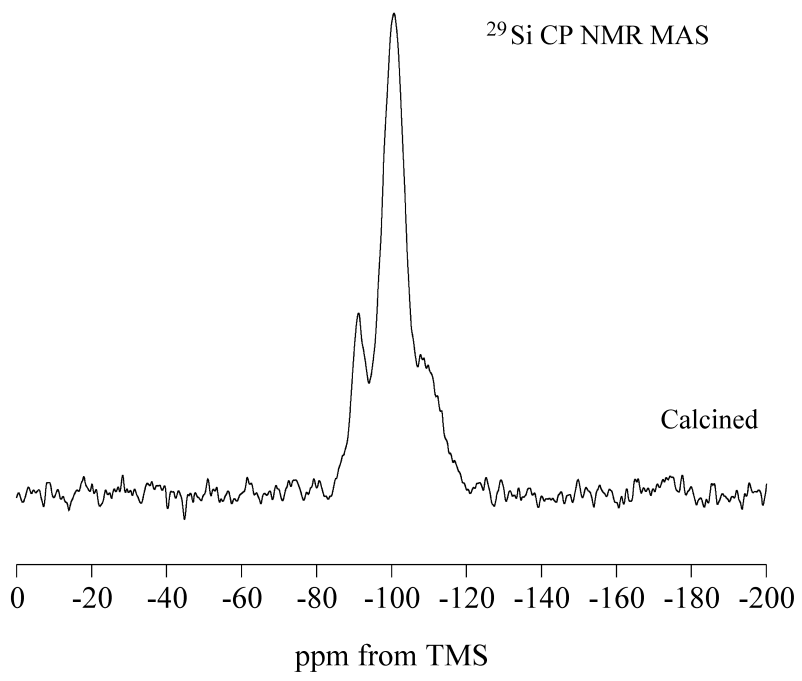

Figure 7. ${ }^{1} \mathrm{H}-{ }^{29} \mathrm{Si}$ CP/MAS NMR spectrum of the AlSiMCM-41 (R/108) sample.

around $0 \mathrm{ppm}$ is representative of hexacoordinated aluminum belonging to extra-structural species formed during calcination $^{13,14}$.

\subsection{SEM micrographs}

Figure 9 presents typical micrographs of the calcined SiMCM-41(R/108) and SiMCM-41(P/48) samples. Formation of the SiMCM-41 phase at hydrothermal conditions under autogenic pressure is seen to result, in shorter time, in a solid consisting of small agglomerates (Fig. 9a). The SiMCM-41 obtained under autogenic pressure, synthesized under reflux conditions (Fig. 9b) presents agglomer-

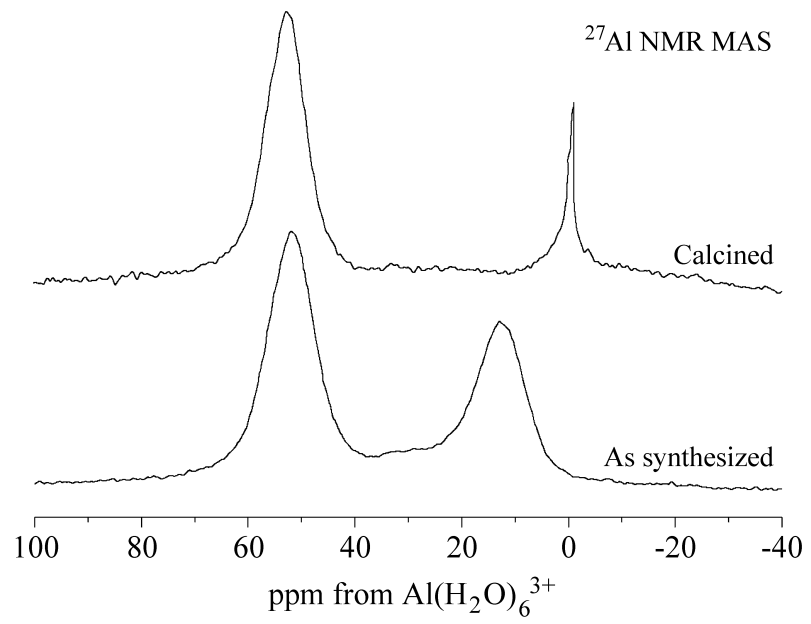

Figure 8. ${ }^{27} \mathrm{Al}$ MAS RMN spectra of the AlSiMCM-41(R/108) samples.

ates, similar to those obtained under autogenic pressure, and worm-like particles; this morphology practically did not change with synthesis time. The AlSiMCM-41 samples exhibit agglomerates with sizes between 3 and $200 \mu \mathrm{m}$, independent of the used synthesis method (Fig. 10). These samples did not show a tendency to form particles with a particular morphology.

\section{Conclusion}

XRD analysis of SiMCM-41 and AlSiMCM-41 samples showed that the MCM-41 phase may be formed by both processes and that the synthesized material in the presence of aluminum and/or under refluxing conditions
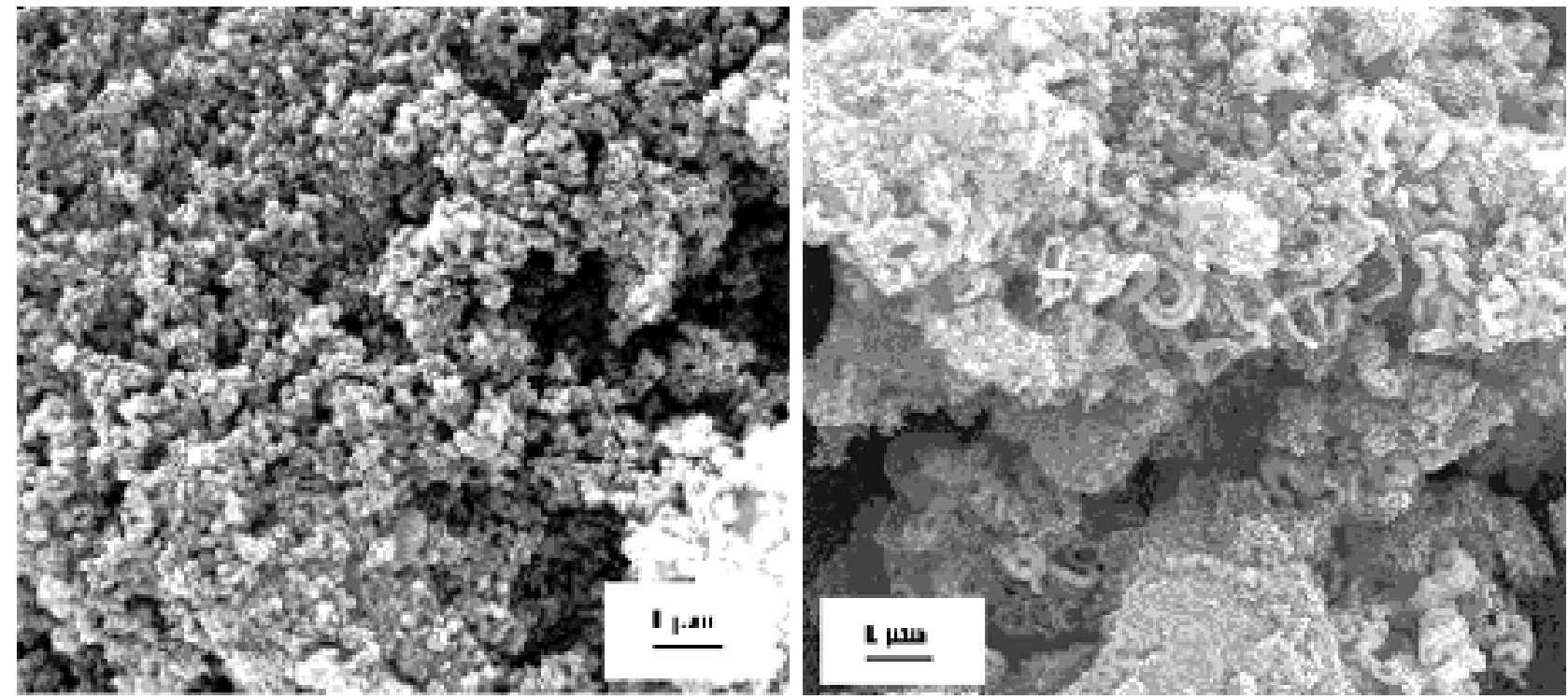

Figure 9. SEM micrographs of the SiMCM-41 samples. (a) Si MCM-41 (p/48), (b) Si MCM-41 (R/108). 

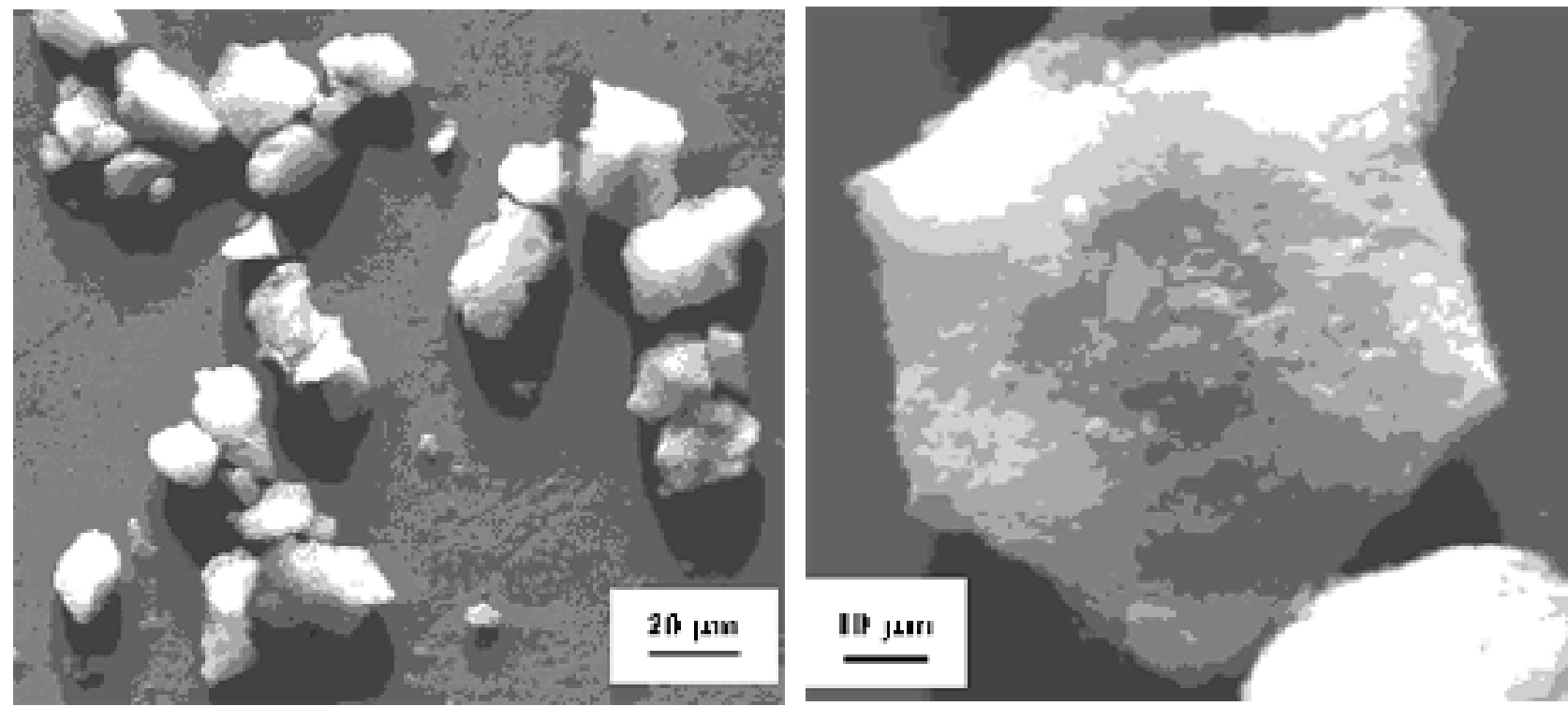

Texto Texto Texto Texto Texto Texto Texto

Figure 10. SEM micrographs of the AlSiMCM-41 samples. (a) AlSi MCM-41 (R/24), (b) AlSi MCM-41 (P/288).

presents a hexagonal arrangement of less ordered mesopores. However, in the latter case, as verified by XRD and physisorption data, improvement in order was observed with higher synthesis times.

${ }^{29} \mathrm{Si}$ MAS NMR and ${ }^{1} \mathrm{H}-{ }^{29} \mathrm{Si}$ C/P MAS NMR spectra showed that a great part of the $\mathrm{Si}$ atoms exist as silanol groups which originate resonance peaks at $-110,-100$ and -91 ppm. The presence of $\mathrm{Al}$ atoms may generate $\mathrm{Si}(3 \mathrm{Si}, \mathrm{Al})$ and $\mathrm{Si}(2 \mathrm{Si}, 2 \mathrm{Al})$ environments which might be contributing to resonance peaks at -100 and $-91 \mathrm{ppm}$. The ${ }^{27} \mathrm{Al}$ MAS NMR spectra of the as synthesized AlSiMCM-41(R/108) confirm a strong resonance peak of tetrahedral framework aluminum close to $53 \mathrm{ppm}$ and two others resonances, one close to 14 ppm attributed to $\mathrm{Al}\left(\mathrm{H}_{2} \mathrm{O}\right)_{6}{ }^{+3}$ species within the pores and the other, a weak signal close to $32 \mathrm{ppm}$ attributed to pentacoordinated aluminum species. ${ }^{27} \mathrm{Al}$ MAS NMR spectra of the calcined sample showed the peak at $53 \mathrm{ppm}$ and another at $0 \mathrm{ppm}$ corresponding to an hexacoordinated extra-framework aluminum species formed during the calcination process.

\section{Acknowledgments}

The authors thankfully acknowledge the financial support for this study provided by FAPESP (grant n. 97/03170 ) and for the Doctor's scholarship granted by CAPES to Rogério A.A. de Melo.

\section{References}

1. Kresge, C.T.; Leonowicz, M.E.; Roth, W.J.; Vartuli, J.C.; Beck, J. S. Nature, n. 359, p. 710, 1992.
2. Beck, J.S.; Vartuli, J.C.; Leonowicz, M.E.; Kresge, C.T.; Schmitt, K.D.; Chu, C.T.W.; Olson, D.H.; Sheppard, E.W.; McCullen, S.B.; Higgins, J.B.; Schlenker, J.L. J. Am. Chem. Soc., n. 114, p. 10834, 1992.

3. Corma, A.; Martínez, A.; Martínez-Soria, V.; Montón, J.B. J. Catal., n. 153, p. 25, 1995.

4. Rathousky, J.; Zukai, A.; Franke, O.; Schulz-Ekloff, G. J. Chem. Soc., Faraday Trans., n. 91, p. 937, 1995.

5. Kim, M.J.; Kwak, J.H.; Shinae, J.; Shinae, Ryong, R. J. Phys. Chem., n. 99, p. 16742, 1995.

6. Feng, X.; Fryxell, G.E.; Wang, L. -Q.; Kilm. A.Y.; Liu, J.; Kemner, K.M. Science, n. 276, p. 923, 1997.

7. Monnier, A.; Schüth, F.; Huo, Q.; Kumar, D.; Margolese, D.; Maxwel, R.S.; Stucky, G.D.; Krishnamurty, M.; Petroff, P.; Firouzi, A.; Janicke, M.; Chmelka, B.F. Science., n. 261, p. 1299, 1993.

8. Carvalho, W.A.; Varaldo, P.B.; Wallau, M. Zeolites, n. 18, p. 408, 1997.

9. Cheng. C. -F.; Zhou, W.; et al. J. Am. Chem. Soc., Faraday Trans., n. 93, p. 359, 1997.

10. Beck, J.S.; Vartuli, J.C. Current Opinion in Solid State and Mat. Science, n. 1, p. 76, 1996.

11. Cui, J.; Yue, J.; Sun, Y.H.; Dong, W.Y.; Gao, Z. Progress in Zeolite and Microporous Materials, Chon, H.; Ihm, H.K.; Uh, Y.S., eds., Stud. Surf. Sci. Catal., Elsevier, The Netherlans, v. 105, p. 687, 1997.

12. Montes, A.; Cosenza, E.; Giannetto, G.; Urquieta, E.; Melo, R.A.; Gnep, N.S.; Guisnet, M. Mesoporous Molecular Sieves, Bonneviot, L.; Béland, F.; Danumah, C.; Giasson, S.; Kaliaguine, S., eds., Stud. Surf. 
Sci. Catal., Elsevier, The Netherlans, v. 117, p. 237, 1998.

13. Rocha, J.; Liepold, A.; Roos, K.; Reschetilowski, W.; Esculcas, A.P.; Philippou, A.; Anderson, M.W. J.
Chem. Soc., Faraday Trans., v. 92, n. 22, p. 4623, 1996.

14.Luan, Z.; Cheng, C.-F.; Zhou, W.; Klinowski, J. J. Phys. Chem., v. 99, n. 1018, 1995. 